\title{
Nuevas herramientas para la docencia de la historia del arte
}

\author{
Núria Feliu Beltrán ${ }^{\mathrm{a}}$
}

${ }^{a}$ Universitat de València, Valencia, España, Nuria.Feliu@uv.es

\section{Resumen}

La propuesta que se presenta en esta comunicación surge de la observación, de las consultas -tanto las más habituales como las más llamativas- de los estudiantes de historia del arte y de algunos vacíos y errores recurrentes detectados tras la evaluación.

Teniendo en cuenta tanto los contenidos curriculares como las competencias reales de los alumnos, hemos ideado un espacio colaborativo on-line en el que los estudiantes puedan compartir recursos e ir elaborando, de manera supervisada, su material de apoyo para el estudio (imágenes, esquemas, fichas, apuntes y etiquetas web), superando algunos tópicos y errores que suelen acumularse tras la búsqueda indiscriminada en internet.

Este modo de trabajar permitirá que los alumnos cuenten con materiales de estudio de buena calidad, al tiempo que se fomentan otras destrezas y capacidades necesarias cuando se trabaja con un volumen de imágenes tan elevado, tales como el adecuado manejo de bases de datos y de herramientas básicas de diseño y de tratamiento de imágenes.

En esta comunicación presentamos el desarrollo de esta propuesta (plantillas, reparto de tareas, métodos de evaluación y supervisión, entre otros aspectos), así como los buenos resultados obtenidos de otras experiencias y prácticas previas que, en cierto modo, nos han animado a diseñarla.

Palabras clave: innovación docente, historia del arte, trabajo colaborativo, nuevas herramientas

\section{Introducción}

No resulta difícil detectar que cada vez más alumnos recurren a internet como fuente para buscar sus imágenes, completar sus apuntes o incluso suplir sus faltas a clase. Tampoco es 
extraño, dada la inmediatez y comodidad que supone la búsqueda y descarga de información en la web. Y no sería reprochable si no relizasen esas consultas de manera superficial y descuidada, acumulando algunos errores y obviando algunas valiosas opciones que ofrecen.

Proponemos un ejercicio que puede ayudarles a elaborar unos apuntes completos y bien organizados, al tiempo que les muestra cómo aprovechar adecuadamente las nuevas tecnologías para facilitar el estudio y la investigación. Compartiendo el esfuerzo y los recursos construirán entre todos, de manera supervisada, el material de estudio complementario de la asignatura.

Puede parecer que con esta propuesta, en cierto modo, estamos fomentando un sustituto a los libros, dado que algunos alumnos, muy probablemente, recurrirán a la biblioteca sólo para completar el trabajo que les haya sido asignado, pero no para consultar otras obras, considerando posiblemente que con los materiales compartidos tienen información suficiente. Sin embargo, esperamos que se produzca el efecto contrario; al compartir su trabajo con el resto de los compañeros, contarán con más referencias y fuentes fiables y accesibles -buscadas y organizadas por ellos- a las que recurrir, promoviendo su consulta actual y futura. Las herramientas que proponemos para su elaboración les permitirán además conocer otras maneras de gestionar sus datos que podrían serles útiles.

\section{Apuntes compartidos: base de datos colaborativa}

\subsection{Objetivos}

-Elaborar, de manera cooperativa, materiales complementarios de estudio o consulta de buena calidad, supervisados por la docente.

-Fomentar destrezas básicas para la investigación, así como otras destrezas a nuestro entender necesarias cuando se trabaja con un elevado volumen de imágenes, tales como el adecuado manejo de bases de datos y de herramientas básicas de diseño y de tratamiento de imágenes.

-Fomentar el trabajo colaborativo, la interacción entre alumnos y el desarrollo de otras habilidades. 


\subsection{Desarrollo de la propuesta}

Basándonos en los contenidos curriculares de la asignatura "Historia del arte precolombino" incluidos en la guía docente ${ }^{1}$ y teniendo en cuenta que se trata de una asignatura -en la Universidad de Valencia- optativa cuatrimestral de cuarto curso, ofertada para un máximo de 40 alumnos, proponemos la elaboración conjunta de los materiales de estudio complementarios a los apuntes de clase a través de un espacio compartido on-line que, finalizado el trabajo, contendrá una base de datos con las fichas e imágenes de las obras más destacadas de la asignatura, una carpeta de bibliografía organizada por temas con artículos, vídeos y referencias bibliográficas de calidad contrastada, así como la carpeta con los materiales de apoyo que ya se les facilitan en la actualidad.

Se propone como una actividad obligatoria y evaluable, con un peso del $10 \%$ en la nota final. Cada alumno deberá elaborar, cumpliendo los requisitos requeridos, al menos la ficha de una obra que seleccinará de un listado (Tabla 1.1) el primer día de clase. Cada una de ellas constituirá una entrada de la base de datos conjunta. Facilitaremos asimismo un listado alternativo para aquellos alumnos que, de manera voluntaria, decidan realizar más de una entrada de la base de datos colectiva.

Deberán completar de manera adecuada los siguientes campos: identificación de la obra, localización geográfica y temporal, cultura, análisis formal (soporte, descripción formal materiales y procedimiento técnico), aproximación al significado (análisis iconográfico e interpretación iconográfica), bibliografía, enlaces (referencias, artículos, vídeos...), palabras clave e imágenes o referencias/enlaces a las imágenes.

En los apartados de cultura, análisis formal y aproximación al significado se requerirán textos de 8.000 caracteres como mínimo. Aunque las obras habrán sido explicadas en clase, deben incluir, además de la bibliografía citada en el texto, al menos cinco referencias bibliográficas y dos enlaces externos relacionados con la obra trabajada o con la cultura a la que pertenece. Las imágenes incluidas, adecuadamente referenciadas, deberán tener calidad suficiente para ser manipuladas por el alumno, que habrá de ser capaz de modificarlas al menos mínimamente (recortar o ampliar detalles de la imagen, iluminar o destacar algunas zonas, colorear motivos, calcar, incluir texto o marcas...).

Inicialmente, los alumnos rellenarán los datos en una plantilla de excel $^{2}$ (Tabla 1.2) y subirán sus imágenes a una carpeta asociada a su entrada, en una tarea individual creada en la plataforma Aula Virtual de la Universidad de Valencia. Una vez corregida la tarea, cada

\footnotetext{
1 Elaborada por la Dra. Cristina Vidal: https://webges.uv.es/uvGuiaDocenteWeb/guia

2 Los datos pueden exportarse fácilmente y permite organizer la información por campos; en caso de que no se disponga del programa adecuado para la elaboración de bases de datos, es una buena manera de organizar la información.
} 
alumno deberá rellenar la entrada correspondiente en la base de datos colectiva (Img. 1) y cargar los artículos y enlaces pertinentes; esos materiales serán validados por las docentes tras una segunda revisión para garantizar la buena calidad de las entradas.

La base de datos se alojaría en el Aula Virtual de la Universidad de Valencia. Aunque el entorno del Aula Virtual permite pocas modificaciones, principalmente en lo referido al diseño, ofrece a los alumnos un primer contacto con bases de datos. Al requerise imágenes modificadas e incluir la carpeta de "Bibliografía y referencias", organizada por temas, se pretende que los alumnos se familiarizen también con programas de gestión y modificación de imágenes, al tiempo que apredenden a organizar sus materiales sin duplicarlos.

Además se propone impartir dos clases de asistencia voluntaria en horario de actividad complementaria para facilitar la labor a los alumnos menos familiarizados con estas herramientas. La primera de ellas, acerca del manejo básico de programas y aplicaciones de diseño y tratamiento de imágenes; la segunda, sobre el manejo básico de bases de datos y bancos de imágenes; tanto en lo que se refiere a su creación, como en adquirir familiaridad con su consulta, dado que cada vez son más las instituciones que digitalizan y comparten sus datos de este modo.

Somos conscientes de que se trata solo de una propuesta y de que no podemos aportar todavía resultados relevantes. Es muy posible que, una vez implementada, tengamos que ir ajustándola, adaptándonos a los recursos disponibles y a su recepción por parte de los alumnos pero creemos que puede ser una herramienta útil, con posibilidades de enriquecimiento posterior.

\subsubsection{Plantillas}

Tabla 1.1. Asignación de entradas

\begin{tabular}{|c|c|c|}
\hline \multirow{7}{*}{$\begin{array}{l}\text { Culturas ceramistas del } \\
\text { Preclásico y Olmecas }\end{array}$} & Cabeza colossal & Alumn@1 \\
\hline & Ofrenda 4 de La Venta & Alumn@2 \\
\hline & Altar 4 de La Venta & Alumn@3 \\
\hline & Pretty Ladies de Tlatilco & Alumn@ 4 \\
\hline & Tumbas de tiro de Nayarit & Alumn@5 \\
\hline & Señor de las Limas & Alumn@6 \\
\hline & El epiclásico y el ciclo de la vida en Xochitécatl & Alumn@7 \\
\hline \multirow{6}{*}{ Teotihuacan } & Plano & Alumn@8 \\
\hline & Templo de Quetzalcoatl & Alumn@9 \\
\hline & Incensario & Alumn@10 \\
\hline & Máscara & Alumn@11 \\
\hline & Tetitla, Pórtico 11, Mural 2. Detalle & Alumn@12 \\
\hline & Tepantitla, Tlalocán y Tamoanchán & Alumn@13 \\
\hline
\end{tabular}


Núria Feliu Beltrán

\begin{tabular}{|c|c|c|}
\hline \multirow{8}{*}{ Mayas } & Murales de Bonampak & Alumn@14 \\
\hline & Templo I de Tikal & Alumn@15 \\
\hline & Lápida de Pacal & Alumn@16 \\
\hline & Dinteles Yaxchilán & Alumn@17 \\
\hline & K1728 & Alumn@18 \\
\hline & Templo de las Inscripciones & Alumn@19 \\
\hline & Estela x de Copán? & Alumn@20 \\
\hline & Códice Dresden & Alumn@21 \\
\hline \multirow{4}{*}{ Aztecas } & Códice Boturini & Alumn@22 \\
\hline & Grabado de Tenochtitlan & Alumn@23 \\
\hline & Piedra del Sol & Alumn@24 \\
\hline & Coatlicue & Alumn@25 \\
\hline \multirow{5}{*}{ Chavín, Paracas } & Plano & Alumn@26 \\
\hline & Lanzón & Alumn@27 \\
\hline & Momia Paracas & Alumn@28 \\
\hline & Estela Raimondi & Alumn@29 \\
\hline & Textiles Karwa & Alumn@30 \\
\hline \multirow{5}{*}{$\begin{array}{c}\text { Moche, Nazca, Chimú y } \\
\text { Lambayeque }\end{array}$} & Estela Raimondi & Alumn@ 31 \\
\hline & Tumbas del Señor de Sipán & Alumn@ 32 \\
\hline & Vasija-estribo ritual funerario & Alumn@ 33 \\
\hline & Tumi & Alumn@34 \\
\hline & Cerámica Pampa Grande, taller de soldado & Alumn@35 \\
\hline \multirow{5}{*}{ Incas } & Esquema cancha & Alumn@36 \\
\hline & Plano Cuzco & Alumn@ 37 \\
\hline & Saccsahuyaman? & Alumn@38 \\
\hline & Macchu Picchu & Alumn@39 \\
\hline & Estereotomía & Alumn@40 \\
\hline
\end{tabular}


Tabla 1.2. Plantilla de Excel que debe rellenarse en la primera fase

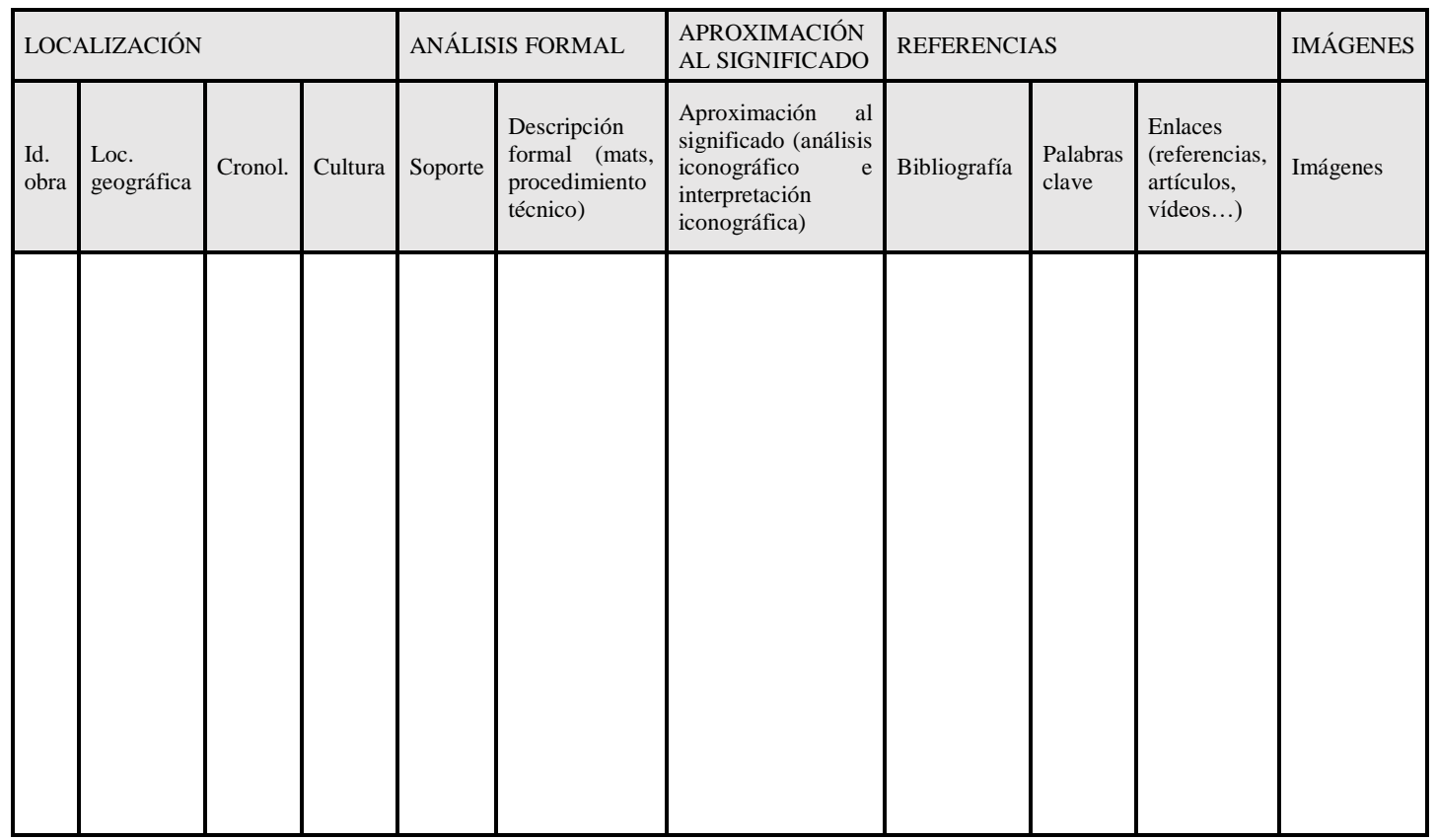

\section{Agradecimientos}

La autora agradece expresamente el apoyo del Ministerio de Economía y Competitividad, a través de la financiación del Proyecto de Investigación "Arte y arquitectura maya. Nuevas tecnologías para su estudio y conservación (BIA 2014-53887-C2-2P)”, dirigido por la Dra. Cristina Vidal; la concesión de una beca FPI en el marco del Proyecto y la incorporación como Personal Investigador en Formación al Departamento de Historia del Arte de la Universidad de Valencia han contribuido de forma determinante a la realización de la propuesta que aquí se presenta. Y a la Dra. Cristina Vidal, nuestra directora de Tesis, con la que hemos compartido la docencia de las asignaturas "Historia del Arte Precolombino" y "Análisis de la imagen" durante estos años y que nos ha facilitado mucho la labor, pues siempre hemos contado con su apoyo.

\section{Referencias}

Araujo, J.C. (2019). El componente social. Un indicador del trabajo colaborativo online. Edmetic, Revista de Educación Mediática y TIC: https://doi.org/10.21071/edmetic.v8i1.11104 
Franco, B., \& Arciniega, L. (2012). El impacto de las nuevas tecnologías en la innovación docente: la creación de un espacio colaborativo on line y la recepción por parte del alumnado. In F.R. Durán, R. López, M. C. Saavedra, J. A. Sánchez and M. Villarino (Eds.), Innovación metodológica y docente en Historia, Arte y Geografía: Actas del Congreso (pp.1121-1127). Santiago de Compostela: Universidade de Santiago de Compostela.

Guitert, M., Romeu, T., and Pérez-Mateo, M. (2007). Competencias TIC y trabajo en equipo en entornos virtuales. Revista de Universidad y Sociedad del Conocimiento (RUSC). Vol. 4, n. ${ }^{\circ} 1$. UOC : $\underline{\text { http://www.uoc.edu/rusc/4/1/dt/esp/guitert_romeu_perez-mateo.pdf }}$

Martín, A. M., Domínguez, M. and Paralera, C. (2011). El entorno virtual: un espacio para el aprendizaje colaborativo. Edutec-e. Revista Electrónica de Tecnología Educativa, 35: http://edutec.rediris.es/revelec2/revelec35/

Ruiz, M., García, M., and Diestro, A. (2012). Competencia digital: la brecha entre lo que hay y lo que debería haber. In L. García (Ed.), Sociedad del Conocimiento y Educación (pp. 285-292). Madrid: UNED.

Serrano, M. and Lozano, E. (2018). Nous espais de col.laboració entre secundaria i Universitat en l'àmbit de la historia de l'art. Revista CIDUI 2018: https://www.arsmemoriae.cat/wpcontent/uploads/2019/02/CIDUI_18.pdf

Serrano, M. and Lozano, E. (2017). Espacios de creación: Innovación y mejora docente en Historia del Arte. Ars Memoriae. In IN-RED 2017, Congreso Nacional de Innovación Educativa y Docencia en Red: http://dx.doi.org/10.4995/INRED2017.2017.6802

Sobrino, D. (2012). La didáctica de la historia del arte con TIC. Algunas propuestas para secundaria y bachillerato. In F.R. Durán, R. López, M. C. Saavedra, J. A. Sánchez and M. Villarino (Eds.), Innovación metodológica y docente en Historia, Arte y Geografía: Actas del Congreso (pp.10561067). Santiago de Compostela: Universidade de Santiago de Compostela.

Vidal, C. (2018). Guía Docente de la asignatura "Historia del arte precolombino". UV: https://webges.uv.es/uvGuiaDocenteWeb/guia?APP=uvGuiaDocenteWeb\&ACTION=MOSTRA $\underline{\text { RGUIA.M\&MODULO }=33901 \& \text { CURSOACAD }=2019 \& I D I O M A=C}$ 